\title{
BIOLOGICAL EUGENICS
}

\author{
Relation of Philanthropy and Medicine to Race Betterment-Study of Genetics \\ Shows that no Race Can be Bred Immune to All Diseases or \\ Defects-Nevertheless, Medicine and Charity Must \\ Pay More Attention to Heredity ${ }^{1}$
}

LEON J. COLE,

Professor of Experimental Breeding, University of Wisconsin.

$I^{\mathrm{N}}$ ACCEPTING the invitation to speak before this Conference on the subject of The Relation of Philanthropy and Medicine to Race Betterment, I wish to make it clear that I do so with no special knowledge of medicine or of sociology. But if by Race Betterment is meant in this instance the production of an inherently better race rather than simply the bettering of conditions-if it means biological improvement rather than social improvement-then I may perhaps avoid the charge of presumption, since neither medical science nor sociology has as yet amassed sufficient data for a very clear understanding of what their biological effects upon the race may be. Consequently the subject may be regarded to a considerable extent in the light of biological analogy, and if such facts as are known fit in with biological theory and deductions in other lines, we may from this gather some assurance that we may apply the reasoning of biology, in its narrower sense, to the destiny of mankind, which is, of course, a cognate field of biology in its broader meaning.

For we must not forget that man is still an animal, however much he may specialize socially; and although he may by his superior knowledge abrogate many of the laws which bind his more lowly kin, the bird, the fish, the maggot, or ameba, he cannot hope to escape from the operation of certain of nature's methods, and one of the most funda- mental and tyrannical of these is that of reproduction. The heritage of society is passed in an uninterrupted flow from one generation to the next; but not so the biological inheritance, for between the individual of one generation and that of the next there is a rearrangement, a shuffling of the cards face down, leading to an indefiniteness of results which has long made this problem one of the most difficult of biological questions.

So it is as a biologist that I propose to discuss the question before us, and I believe you will agree that until we have enough facts to enable us to see definitely what medicine and philanthropy are actually doing for the race, we shall have to predict as best we can what they will probably do from our knowledge of general biological laws; and our predictions will have value directly in relation to the correctness and extent of our knowledge of these laws. This becomes at once apparent when we consider the diametrically opposed attitudes of certain biologists, sociologists and social reformers. One believes that the human race already possesses the potential factors for a richer and fuller life, that this more or less latent potentiality is rather universally distributed, at least within certain group limits, ${ }^{2}$ and all that is needed is a better environment to bring it out. Such maintain that biological evolution has largely stopped in the case of civilized man, and that social evolution,

\footnotetext{
1Address (here abridged) delivered before First National Conference for Race Betterment, Battle Creek, Mich., January 8, 1914.

"See for example Smith, S. G., "Social Pathology," New York, 1911, section on Eugenics, especially pp. 308 and 309.
} 
the evolution of the environment, has completely taken its place. Thus Smith in his Social Pathology, asserts that while "Charles Darwin may learn important lessons from pigeons and pigs, and a brood of lesser men may talk about human marriage in the terms of the stock farm,. . . the men of our generation who are studying the problems at closer range will more and more discuss them in terms of social psychology." Another holds that evolution and selection, or evolution by selection, is in effect as always; that the potentialities of individuals differ, and that they develop differentially according to this inherited potentiality and to the limiting influence of the environment. Furthermore, that such individuals as are able to survive the environment and to produce offspring, bequeath to their successors only that which they themselves inherently possessed. Or still others, while believing that Natural Selection is biologically operative, attribute to the environment an ameliorating effect upon the germ plasm, which means the "inheritance of acquired characters." When men differ to this extent in their interpretation of natural laws, is it surprising that they fail to agree on specific means for race betterment?

\section{PHILANTHROPY AND MEDICINE.}

At first thought it might seem odd that philanthropy and medicine should be classed together in a discussion of this nature. The former draws upon the resources of the individual, or of the state, if we use the somewhat broader word charities, while the latter is ordinarily a source of income and livelihood to the individual practicing it. In this sense the same might be said of agriculture or manufacture. But medicine and philanthropy have this in common - the one tends to relieve the want, the other the suffering, and both often to prolong the life of the recipient. And for this last reason they are both of the same immediate eugenic importance. I shall therefore treat of them together in general, discussing specific instances from one or the other as the case may be.

Almsgiving and charity are as old as history, and it is generally conceded that these give advantage to the biologically and sociologically unfit which enable them to live longer and to propagate more than they normally would. But with one or two exceptions, until recently, no thought was given, so far as we know, to the possible influence of this upon the race. Nevertheless, to quote Warner," "Plato, more than two thousand years ago, warned his countrymen of the degradation in store for any nation which perpetuated the unfit by allowing its citizens to breed from enervated stock; and he sketched for them an imaginary republic in which no considerations of inheritance, of family ties, or of pity were permitted to stand in the way of the elimination of the weak and the perfection of the race."

With the rise of the study of economics these questions often came to the fore, and then the whole matter was given a new turn by the revolutionary ideas of Natural Selection which permeated so many fields after Darwin's publication of the "Origin of Species." Biologists and others were not slow to apply the new ideas to man's racial development, and from this time really dates the period of active discussion, and often violent disagreement, on the relation of social advance to race improvement or degradation.

As social reformers were concerned with bettering the environment, a work which could often be seen to produce immediate and marked results in adding to the health and material comfort of the populace as a whole, the gradual almost complete acceptance by biologists of Weismann's doctrines as to the noninheritability of environmentally produced modifications naturally led to a widening of the breach between those who placed their faith in social measures and those who foresaw the direful effects

Loc. cit., p. 304.

4"The most obvious result of charity as a selective force has been to lengthen the lives of the individuals cared for."-Warner, A. G., "American Charities," New York, 1908, p. 23.

"American Charities," 1908, p. 20. See also, Pearson, K. "The Scope and Importance to the State of the Science of National Eugenies," Eugenics Lab. Lect. Series, I., 1909. pp. 23, 24. 
of what they believed to be the increasingly disproportionate ratio of defective racial germ plasm. The social reformer was accused of being shortsighted, like a mariner driving his ship ahead because the wind is fair and the weather looks pleasant, but utterly regardless of hidden shoals. Or he might be likened to the unscientific farmer who, because a particular crop is profitable, grows it year after year in the same ground without rotation until the land is depleted or "sick" and will no longer produce. Or again, like the capitalist who razes the forests or despoils the earth of minerals with all thought to his present gain, and none for future generations.

On the other hand those who called attention to the biological consequences of the withdrawal of selection were called "dismal scientists" and alarmists; it was maintained that "the mutilation or destruction of the unfit would make society as a whole increasingly cruel. It would produce a despotism of pseudo-science that would be more crushing to all the gentler virtues of men than any political despotism ever known."

\section{WARNER'S ATTITUDE.}

Between the views outlined above we find that intermediate positions have been taken by a large group both of social workers and of biologists. A few examples may serve to illustrate. Warner, who during his short life was one of the foremost social workers in America, far-sighted and discriminating, though primarily interested in practical charities, clearly recognized the importance of heredity in racial progress. $\mathrm{He}$ nevertheless emphasizes the value to the race of altruistic sentiments, though he recognizes the necessity of prevention of multiplication of the unfit. Thus he says:" "Could we cheaply rid ourselves of incapables and close our hearts to the appeals of distress, we might never have the compulsion put upon us of seeking out the wiser plans, which may eventually give us a more uniformly healthy race. Extermination might be an easy cure for pauperism, but it would be a costly remedy biologically; and if we allow our instincts to compel us to forego the use of it, we may ultimately be driven to preventive measures." He is doubtful, however, as to the efficacy of sterilization, and is inclined to the view which is now gaining wide acceptance that the most efficacious remedy is going to be segregation. He points out that in many of our almshouses there are sometimes inadequate means of separating the sexes, and "the breeding of paupers goes on upon the premises," and even that "formal marriages between almshouse paupers have very frequently received the sanction of both church and state." $\mathrm{He}$ concludes his chapter with the following very sane statement: "Certain it is that while charity may not cease to shield the children of misfortune, it must, to an ever increasing extent. reckon with the laws of heredity, and do what it can to check the spreading curse of race deterioration. The desire to prevent suffering must extend to the desire to prevent the suffering of unborn generations."

Among those who have in their treatment of this subject emphasized the importance of the Natural Selection. viewpoint may be mentioned especially Herbert Spencer, Francis Galton and Karl Pearson, the director of the Galton Laboratory for National Eugenics, though many other names might be mentioned as well. The last named has turned the energies of his laboratory to studying by means of highly developed statistical methods the inheritance of various diatheses, traits and defects, as well as the effects of ameliorative measures. In his Cavendish Lecture for 1912, entitled "Darwinism, Medical Progress and Eugenics,"" we find his position well set forth. After marshalling the data of his laboratory to prove that "general health is inherited and that the infantile death-rate is selective," he sums

\footnotetext{
"Smith, "Social Pathology," 1911, p. 294.

'Loc. cit., p. 25.

Loc. cit., p. 31.

'Eugenics Lab. Lect. Series, IX, 1912.
} 
up so well that I cannot refrain from quoting. He says: ". . . these are individual illustrations of what is happening, because the intensive selection of the old days has been suspended. That suspension is partly due to medical progress; you are enabling the deformed to live, the blind to see, the weakling to survive-and it is partly due to the social provision made for these weaklings--the feeble-minded woman goes to the workhouse as a matter of course for her fourth or fifth illegitimate child, while the insane man, overcome by the strain of modern life, is fed up and restored for a time to his family and paternity. In our institutions we provide for the deaf-mute, the blind, the cripple, and render it relatively easy for the degenerate to mate and leave their like. In the old days, without these medical benefits and without these social provisions the hand of Nature fell heavily on the, unfit. Such were numbered, as they are largely numbered now, among the unemployables; but there were no doctors to enable them to limp through life; no charities to take their offspring or provide for their own necessities. A petty theft meant the gallows, unemployment meant starvation, feeblemindedness meant persecution and social expulsion; insanity meant confinement with no attempt at treatment. To the honour of the medical profession, to the credit of our social instincts, be it said, we have largely stopped all this. We have held out a helping hand to the weak, but at the same time we have to a large extent suspended the automatic action whereby a race progressed mentally and physically.

MEDICAL PROGRESS vS. EUGENICS.

"Surely here is an antinomy-a fundamental opposition between medical progress and the science of national eugenics, or race efficiency. Gentlemen, I venture to think it is an antinomy, and will remain one until the nation at large recognizes as a fundamental doctrine the principle that everyone, being born, has the right to live, but the right to live does not in itself convey the right to everyone to reproduce their kind.

"Our social instincts, our common humanity enforce upon us the conception that each person born has the right to live, yet this right essentially connotes a suspension of the full intensity of natural selection. Darwinism and medical progress are opposed forces, and we shall gain nothing by screening that fact, or, in opposition to ample evidence, asserting that Darwinism has no application to civilized man."

I have made these quotations frankly and at length because I believe they will show you, more faithfully than I could perhaps have done it in my own words, the positions held by various students of race progress and betterment. I believe that any reasonable person must agree with Pearson that in spite of the masking influence of the increasingly complex social heritage which is passed on from generation to generation in our customs, beliefs, books, laws-in fact in all our increasing knowledge of science and the arts-nevertheless biological inheritance is operating in man now on the same principles that it did when he swung the stone axe, or scuttled through the trees with his simian congeners. The detailed studies of individual lines of inheritance which have in recent years been made from the Mendelian viewpoint ${ }^{10}$ leave no doubt of this. Furthermore, this being true, it must be conceded by all thinking persons at all conversant with biological principles that selection plays the same role in directing the course of heredity, that is the surviving line of germ plasm, that it always has. Note that I say selection here rather than Natural Selection, for the latter term is associated in many minds with the crude methods of Nature uninfluenced by sentient forces. Will anyone deny that the animal or plant breeder utilizes the same principles of selection in breeding his cattle or his corn that have in Nature brought about the evolution of one form from another? The difference is that instead of being Natural selection it is now conscious

\footnotetext{
${ }^{10}$ For a summary treatment of these see Davenport, C. B., "Heredity in Relation to Eugenics," New York, 1911.
} 
selection on the part of the breeder, and he directs the processes of change, in so far as his art enables him, along the lines which his needs or his fancy direct.

Now as man's mental capacities began to develop the course of selection shifted increasingly on to these, and they became more and more important as his social relations and capacities grew. I am not prepared to assert that the minds of the highly civilized ancient peoples, such as the Greeks, the Egyptians, or even more remote cultures might not be capable of assimilating and utilizing to the full the complexities of our present social and political conditions, our inventions and our scientific knowledge-indeed recent Japanese history would be argument in favor of such a view; but certainly this cannot be said of the more primitive races, and therefore some mental evolution must be postulated from such a condition To my mind the course of evolution presents a picture somewhat like that of a small stream of water making its way down an almost level but slightly irregular surface. Tongues are sent out this way and that as slight depressions lead here and there, and at times a considerable course may be made more or less consistently; but then a higher obstruction is reached and a new course started, determined by the point of lowest level. No matter how well one branch has progressed, if another finds a lower spot it diverts the stream. Just so races and civilizations have arisen and prospered and flourished until others superior in brute strength, in organization, or in equipment in arms, have come in and superseded them.

\section{DEPECTIVES GROW IN NUMBER.}

Until social customs became comparatively highly developed individual physical prowess was as necessary to existence as among the lower animals. This was in the stage of individualism. With specialization, as particular classes in a community took up certain special tasks, and especially as armies were formed not including the total population, physical selection became relaxed for some of the individuals. These conditions have become more pronounced unitil modern philanthropy and medical science are bringing them to $\mathrm{a}$ point where they can no longer be ignored. Neither the greater diligence in seeking them out nor the fact that they remain in institutions for longer periods will account for the disproportionately increasing number of defectives and criminals in our population. This fact seems demonstrated and one does not merit the epithet of alarmist for pointing it out. And if true, must we not give thought to its remedy?

Just as, when the human race developed from the savage, artful means of preservation superseded purely physical, and as the breeder has replaced fortuitous natural selection by conscious selection, so I believe the time is at hand when mankind will find it necessary to substitute some form of rational selection for the hit-or-miss, happy-golucky way they have drifted along in the past. Exactly what this method shall be I do not think we are in a position at the present time to say. Two chief lines seem open, restrictive and constructive-sometimes called negative and positive eugenics. The quotations which have been made in the earlier part of this discourse show clearly, it seems to me, that the former measures may be adopted under certain conditions without doing violence to the finer instincts of the race, without in any way destroying or lessening altruism or humanitarianism. In our nationwide agitation for conservation we are just beginning to realize our duty to future generations. The case is a close parallel, for we are saying that the material benefits of our forests, our minerals and our water power must be conserved for the benefit of all the people, and not reaped now to enrich a few individuals and to be passed on only to their families. Shall we have less foresight in the heritage of defectives and cripples that we pass on to the next and future generations? Is not the social reformer who does not take this into consideration spending all his thought on bettering the present generation, just as exhausting our national resources might enrich this generation but pauperize the next? 
Now, if it is going to be necessary for us to practice some degree of rational selection, we must be sure that it is rational-it must be based upon positive knowledge. What has modern biological research to offer in the way of contribution to such knowledge? In the first place we can readily see that a large part of the disagreement which has been mentioned is due to difference in opinion as to the influence which the environment may have on the individual and on the offspring. It is the old question of Nature and Nurture. While I am free to admit that in its abstruse aspects this is one of the most difficult questions confronting the biologist, I believe that much unnecessary confusion and needless discussion has resulted from the tendency of writers to exaggerate their views either on the one side or the other, and not to accord the question fair treatment. When I am asked, as often happens, which I consider of greater importance, heredity or environment, I commonly give a Yankee reply by asking in return, Which is of more importance for sustaining life, food or air?

\section{INFLUENCE OF ENVIRONMENT.}

Although we may concede what is the almost universal biological opinion of today, that the effects of environment are not in the crude sense heritable, we must not, nevertheless, lose sight of the fact that the environment is a most inportant determining factor in evolution and in selection. This may perhaps best be illustrated by an example. Let us suppose two cows, one of which is inherently a low producer, and is incapable of producing any considerable quantity of milk beyond that necessary to raise her calf. The other, on the other hand, has inherited the capacity to produce a large quantity of milk under certain conditions, namely proper feeding, care and handling. Now let us first consider these animals under, say, range'conditions, where they receive no special care, and where they have to hustle for their own maintenance. So far as milk production is concerncd they will measure up about the same-each will produce enough to' raise her calf and no more -and very likely the inherently low-producer will be at an advantage under these more severe conditions. But now take the two animals and place them in a modern dairy with scientifically prepared rations. and the best treatment that modern dairy practice can provide. What is. the result? The animal which inherited the capacity to respond to such treatment does respond at once by a sustained increase in the flow of milk; but the other does not. The former was hampered by conditions in the first place, but the latter is now absolutely prevented by her nature from the possibility of a response to the improved conditions. We see therefore that these conditions were necessary to make apparent the differences which existed in the hereditary make-up of the two animals. Is not the same true of the human race? It is only by giving opportunity to all, that we may know which are capable of profiting by that opportunity. The good environment then is necessary for differentiation, and without differentiation how may we hope to make selection?

Two other biological concepts are of importance. These have grown out of recent Mendelian investigations. The first is the idea of hypothetical factors, which are definite heritable units, and upon the presence of one or more of which all the characters of an organism depend. Since the factors behave for the most part independently in inheritance, the problem of handling them in selection becomes an extremely complex one. Where only two factors are concerned, any desired combination as to their presence or absence may be expected in at least one of sixteen individuals in the second generation. But as the number of factors to be dealt with increases, the number of individuals necessary to give all the combinations increases at a most disproportionate rate, as is indicated in the following table, which shows the number of individuals which according to expectation would be necessary to produce at least one individual with each 
of the possible combinations under the conditions most favorable for bringing them about:

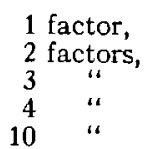

Certain conditions, such for example as certain striking defects or abnormalities, may depend upon the presence or absence of a single factor, and it might be comparatively simple to deal with such cases singly. But the difficulty of dealing with any considerable number, especially in the case of man where conditions are very different from those of animal or plant experimentation, may be readily appreciated. It might be possible by prohibiting by law certain marriages and encouraging others to breed a race of mankind free from the diathesis toward a particular disease, let us say; but think of the number of diseases alone with which man has to contend and consider again the above table. And then tell me how soon eugenics is going to produce an "ideal race," made to order, as the newspapers would have us believe is its aim.

Such speculations may do for the visionary who likes to speculate what the world may be like a century or twenty centuries hence; but the practical eugenist is merely trying to determine how what knowledge we have gained to the present may be turned to the best advantage for race improvement as distinguished from individual amelioration. At the present time it would seem that we are in a position to apply certain phases of restrictive eugenics with comparative certainty of results, such for example as the cutting off of those definitely defective lines of germinal protoplasm which are beyond hope of hereditary improvement.

\section{POSSIBILITY OF SEGREGATION.}

As to the methods which shall be employed, it is coming. I think, to be generally conceded that permanent segregation, at least during the period of reproductive capacity, is going to prove the most feasible if not the most effective of restrictive eugenic measures. But we must be certain of whom it is necessary to segregate. The recent advance of knowledge in this line has been considerable, but it is only a beginning, and I must say that it is due more to the work of biologists than of physicians. Experimental breeding of plants and animals has supplied the keys which have unlocked some of the puzzles of human inheritance, but what we need now are more facts, the facts which can be gathered from the hospitals and asylums, from vital statistics and from the case records of practitioners. But these facts must be gathered with a fullness and accuracy, and with a view to the purpose they are to serve, which has not been customary in the past. It is a deplorable fact that comparatively few medical men have very clear ideas of heredity, or indeed evince much interest in the subject, and few realize its importance.

I have not had time in this discourse to touch upon specific diseases, operations and charitable procedures, and to discuss their relation to the question in hand as I should like to have done. It has no doubt occurred to many of you to ask, however, suppose we grant the necessity of restricting the reproduction of the obviously unfit, what about operations in other cases, the treatment of endemic and epidemic diseases, and the like? Is removing the appendix or the tonsils or the turbinal bones going to be to the race like the drug habit to the individual-once begun, having to be continued in ever-increasing doses? It may be. It is possible that the popular idea of the predicted "hairless, toothless race" may not be so far from the mark, or at least that this type shall increase in numbers unless sentiment against it becomes so strong as to become a selective factor. I wish merely to point out that the filling and crowning of our teeth is not going to insure better teeth for the next generation any more than wearing a set of false ones would; if selection is eliminated, the individuals of the next generation will have to take their chance of inheriting a better or a worse dental battery than their parents. My point is simply, that if the inheritance of the factors concerned were 
understood, by selection of the parents good teeth could undoubtedly be insured to the next generation. But the question would have to be asked, would it be worth while? The breeder knows how hard it is to fix a number of characters at one time, and the student of genetics understands why; and while effort was being concentrated on the teeth other characters would run riot. The difficulties are further magnified by the fact, greatly emphasized in recent studies, that the way in which a character will be inherited often cannot be determined by its appearance in the individual. This is a fact which has been almost completely overlooked or ignored in the discussions of sociologists. So the conservatively inclined need not be alarmed that practical eugenics will do much more than to eliminate the more obviously unfit for some time to come.

If time permitted I should like to discuss the question of whether, in the case of certain specific diseases, such for example as tuberculosis, the greater promise for the race lay in selective heredity, or in environmental adjustments, such as prophylactic measures, antitoxins, treatment and the like. My feeling is that in most of these specific cases the race will find it most expedient to do as now, except in such diseases as denote general physical or mental defect or weakness. Take the case of cancer for example. Suppose it were found to be definitely inherited, but that medical science could find an easy and early diagnosis and certain cure. Would it not be simpler and easier to cure it as it appeared, even though its incidence should be even larger than now, than to cut off all affected lines of germ plasm? For certainly the stock that would be eliminated by such measures would be an inestimable loss to the world.

The very specificity of disease coupled with the difficulty of selecting for a large number of characters at once, and taken in connection with man's present cosmopolitanism, by which all diseases are becoming distributed all over the world within their possible ranges-all these factors make the breeding of a race of mankind immune to all, or even to a large number of diseases, a practical impossibility.

Eugenic selection must, I believe, for a long time be confined as I have said to cases of marked defect and weakness. In addition more study must be given to those influences which may weaken the germ plasm directly, such as alcohol. And medical science, rather than desisting, must push on, especially in the field of general prophylaxis, but with more thought to succeeding generations and the future of the race than it has given in the past. Philanthropy and charities cannot stop, but they must take more counsel of established sciences, and. like medicine, give more thought to the future.

\section{Left-Handedness}

As left-handedness is an inherited character, apparently behaving as a Mendelian recessive, it is interesting to note the belief of some investigators that it is one of the stigmata of degeneracy. Bardeleben is quoted in German periodicals as saying:

"That a few great men, such as Leonardo da Vinci, were left-handed, does not neutralize the prevalent belief-in all ages-that left-handedness implies a sub-standard subject. The percentage of left-handed recruits is but 6.8 ; of school children somewhat higher. These figures are very deceptive, however, for of the left-handed children who became right-handed, the percentage is some 26 . This, added to the persistently left-handed, raises the original percentage of left-handed considerably."

After pointing out that the gibbon and orangoutang are as a rule right-handed, and the gorilla and chimpanzee left-handed, the speaker decided there was no evidence at all that a left-handed person was mentally or physically inferior. 